\title{
A RECONSTRUČ̃̃O DO CONHECIMENTO NA PESQUISA SOCIAL E EDUCAÇÃO
}

Karina Limonta Vieira ${ }^{\mathrm{I}}$

I Universidade Livre de Berlim, Berlim, Alemanha; kalimonta@gmail.com

Bohnsack, R. (2020). Pesquisa social reconstrutiva. Introdução aos métodos qualitativos. Vozes.

A pesquisa qualitativa, nas ciências sociais e educação no Brasil, constitui-se um campo que prioriza pesquisas compostas de um universo heterogêneo de métodos e técnicas, principalmente influenciada por procedimentos norte-americanos. Diante disso, considera-se que a pesquisa empírica de tradição alemã, assim como a pesquisa social reconstrutiva, até os anos 2000, são pouco conhecidas no Brasil (Weller, 2020). Esse tipo de pesquisa agrega às ciências sociais e à educação o conhecimento sobre a realidade social pesquisada. A obra de Bohnsack vem apresentar para pesquisadores o suporte teórico e epistemológico da pesquisa social reconstrutiva, a quem interessa desvendar, construir e reconstruir a realidade social em sua pesquisa.

O sociólogo alemão Ralf Bohnsack publica pela primeira vez no Brasil a obra Pesquisa social reconstrutiva. Introdução aos métodos qualitativos, que está em sua nona edição alemã, cuja primeira versão data de 1991. A obra apresenta e debate aspectos teóricos de sua abordagem para a pesquisa qualitativa. Bohnsack trata criticamente a padronização da pesquisa social levando em consideração os aspectos reconstrutivos da realidade social, ou seja, a reconstrução dos processos pelos quais a realidade social é criada em sua estruturação significativa.

A obra surge da prática de pesquisa do autor, cujo procedimento empírico e metodológico está em desenvolvimento há mais de 30 anos na Alemanha. Bohnsack tem como suporte teórico a sociologia da cultura e a sociologia do conhecimento de Karl Mannheim, fundadas na década de 1920. $\mathrm{O}$ autor discute, inicialmente, diferentes procedimentos utilizados na pesquisa social reconstrutiva para a construção de teorias fundamentadas empiricamente, entre outros, a sociologia do conhecimento hermenêutica, a hermenêutica objetiva, o método documentário, a análise de conversação, a análise de narrativas e a análise do discurso com base na sociologia do conhecimento.

Diante do exposto, Bohnsack apresenta uma obra densa e minuciosa no que diz respeito à fundamentação epistemológica e conceitual dos métodos da pesquisa social reconstrutiva. Por isso, esta resenha apresenta os 12 capítulos como maneira de mostrar a riqueza da obra e não se furtar aos detalhes dos métodos tão bem apresentados pelo autor. Ao final, apresento uma análise sobre a contribuição dessa obra para a pesquisa qualitativa nas ciências sociais e educação no Brasil.

$\mathrm{Na}$ Introdução, o autor apresenta a obra como um livro introdutório que surge do seu contexto da experiência e diálogo na docência, ou seja, de sua prática de ensino e de pesquisa. Essa breve introdução remete ao questionamento principal da obra que pode ser considerado o cerne da pesquisa social reconstrutiva: "Quando as técnicas e os produtos de pesquisa perdem seu vínculo com 
a experiência cotidiana e com a sensibilidade ali arraigada, os resultados são pobres e não ocorre uma ocupação produtiva crítica com a experiência cotidiana” (Bohnsack, 2020, p. 20). Segundo o autor, é nessas condições de produção de conhecimento e de teorias que encontramos as raízes dos problemas centrais da relevância prática da pesquisa sociocientífica. Isso significa dizer que a pesquisa qualitativa exige maior entendimento teórico e epistemológico do processo de construção do conhecimento com base na empiria.

O segundo capítulo, "Métodos reconstrutivos na pesquisa social empírica em distinção aos procedimentos de teste de hipóteses", aborda e critica a metodologia dos procedimentos de teste de hipóteses, a metodologia dos métodos reconstrutivos e reconstrução da reconstrução. A crítica apresentada por Bohnsack nesse capítulo sobre os procedimentos de teste de hipóteses diz respeito ao problema da padronização, que restringe a comunicação da pesquisa e, por isso, a validade de um procedimento é questionada se de fato o método é adequado ao seu objeto, à sua ação social e à comunicação do objeto de pesquisa e quando a teoria é excluída da observação em detrimento da lógica da pesquisa.

"O método documentário" é o terceiro capítulo e explora a prática de pesquisa do método documentário e a metodologia da interpretação documentária. A prática de pesquisa é denominada de reconstrutiva, pois as etapas da pesquisa, os passos de levantamento e de apuração foram desenvolvidos durante o processo de pesquisa, portanto não podem ser deduzidos de princípios metódicos gerais, e a relação com o objeto da pesquisa foi construída tendo como base a realidade empírica. $\mathrm{O}$ método documentário desenvolvido por Ralf Bohnsack tem como âncora central a sociologia do conhecimento de Mannheim, cuja base consiste em considerar que interpretar e compreender estão vinculados a dois modos de experiência ou de socialidade, a experiência conjuntiva e o relacionamento comunicativo dependentes da coletividade e da reflexão.

"A hermenêutica objetiva", capítulo 4, explica a forma e a reconstrução do procedimento da hermenêutica objetiva. Esta tem interesse na análise empírica das estruturas de sentido latente de interação na socialização, ou seja, contexto interno e externo, que se constituem por dois princípios básicos em sua forma, como a variação do contexto enquanto experimento mental e o procedimento de análise sequencial como uma estrutura processual podendo ser identificada por meio de uma reconstrução sequencial de decursos da interação, discursos e narrativas. Nesse sentido, a hermenêutica é denominada objetiva em virtude da pretensão de compreender seu objeto de modo reconstrutivo advindo da regularidade da ação social, da comunicação, da reflexão e da interpretação.

$\mathrm{O}$ autor, no capítulo 5, se preocupa em demonstrar "algumas diferenças entre o método documentário e a hermenêutica objetiva”. O método documentário foca onde o estranho deve ser compreendido e é resultante de um arraigamento existencial ou experiencial por meio da reconstrução de sentidos alheios em que ocorre a relativização ancorada na realidade cotidiana ou na teoria, enquanto a hermenêutica objetiva parte da problematização do contexto externo e interno que segue o próprio objeto, ou seja, o processo real da constituição e reprodução da particularização em geral.

No capítulo 6, "Entrevista narrativa", os fundamentos teórico-narrativos e os fundamentos teórico-biográficos presentes na entrevista narrativa são discutidos. $O$ centro da metodologia da entrevista narrativa desenvolvida por Fritz Schütze ocupa-se dos diferentes níveis da formação das experiências no cotidiano que são um meio familiar e comum para comunicar algo que diz respeito a nós mesmos ou algo que vivenciamos. Os fundamentos teórico-narrativos e teórico-biográficos dizem respeito às conceituações metateóricas ou formais, pois formam a estrutura para a empiria e procede de modo reconstrutivo, porque a teoria da narrativa informa a estrutura formal das narrativas e a teoria da biografia possibilita o acesso à estrutura formal da experiência cotidiana biográfica, ou seja, à formação do habitus no curso da vida.

"O procedimento do grupo de discussão e a análise conversacional” é o capítulo 7 e está relacionado com a pesquisa em meios sociais e a análise conversacional do método documentário 
no contexto dos procedimentos sociolinguísticos. O grupo de discussão consiste em um método de reconstrução de espaços de experiência conjuntiva de meios sociais, no qual o coletivo é evidenciado, ou seja, as experiências coletivas são compartilhadas em seus contextos de vivências comuns. No contexto de procedimentos linguísticos, a análise conversacional envolve vários aspectos como a conversa como um sistema autorregulador, a atualização dos espaços de experiência conjuntiva na conversa, análise conversacional documentária e análise de contextualização, as metáforas de foco e a organização discursiva da análise conversacional documentária e espaços de experiências conjuntivas.

O capítulo 8, denominado "Compreender - Interpretar - Construção de tipos", mostra os passos da interpretação textual, a construção de tipos como análise processual e a construção de tipos. É importante entender na pesquisa social reconstrutiva o significado de compreensão como percepção mental e pré-reflexiva das formações e interpretação como explicação teórico-reflexiva do compreendido no sentido de Mannheim. A construção de tipos como análise processual deve ser compreendida no sentido da interpretação sociogenética ou documentária e envolve a interpretação formulada (imanente) e a interpretação refletida (documentária), por meio da interpretação das próprias orientações, teórico-conceitual e da identificação do contexto de vivências, ou seja, seu habitus.

"Procedimentos qualitativos de interpretação de imagens e o método documentário" constitui o capítulo 9 e diz respeito à teoria e metodologia de uma interpretação qualitativa de imagens com base no método documental. $\mathrm{O}$ autor aborda a marginalização da imagem nos métodos qualitativos, a compreensão por meio da imagem versus compreensão sobre a imagem, a iconologia e método documentário, produtores de imagens representantes e representados, iconicidade e método documentário, as correspondências entre importantes metodologias de interpretação de imagens, o teor do sentido iconográfico ou conotativo, a reconstrução da composição formal da imagem, a análise sequencial versus variação composicional e o conhecimento ateórico e método documentário.

O capítulo 10, "Interpretação documentária de vídeos e filmes", discute sobre os desafios que os métodos de interpretação de imagens enfrentam ao levar em conta a dimensão visual apenas como uma função complementar da dimensão verbal, a análise de conversações. O ponto central do método documentário consiste, então, no acesso à lógica intrínseca do pictórico ou visual e das formas de expressão física. A "aspectualidade, condicionamento local e validade da interpretação" são abordados no capítulo 11. A aspectualidade da interpretação ou estrutura aspectual do conhecimento é uma das consequências das condicionalidades sociais, condicionamento local ou determinação existencial. Eles são a contemplação dos espaços de experiência por meio da força constitutiva da experiência conjuntiva e possibilitam uma compreensão abrangente da aspectualidade do conhecimento e do pensamento, desenvolvendo os fundamentos da postura genética ou interpretação sociogenética para se chegar à validação da interpretação.

Por fim, o interesse do autor, no capítulo "Metodologia praxeológica”, é o estabelecimento de métodos na prática social e sua justificativa metodológica pela via da reconstrução dessa prática, a fundamentação praxeológica de métodos, de modo a considerar que o envolvimento de pesquisadores em uma prática de ação científica e extracientífica resulte em um conhecimento de experiência, visto que é essencial para a percepção e para a criatividade na construção de teorias.

Essa é uma obra relevante para a pesquisa na Alemanha, mas também significativa para a pesquisa nas ciências sociais e educação no Brasil, principalmente com a utilização do método documentário, da entrevista narrativa e do grupo de discussão. Os destaques para essa obra dizem respeito à sua primeira tradução para o português e como suporte fundamental e complementar aos trabalhos já realizados no Brasil e aos que estão ainda por vir. A pesquisa social reconstrutiva contribui para o avanço nas ciências sociais e educação no Brasil, pois permite investigar com outros olhares temáticas como juventude, gênero, relações étnico-raciais e processos institucionais sociais e culturais. Um exemplo são os diversos trabalhos empíricos já realizados no campo das ciências sociais e educação desde os anos 2000, dos quais destaco alguns, como: metodologias na pesquisa qualitativa em educação, grupos de discussão com professores e com estudantes universitários e estudantes do ensino fundamental e médio, entrevistas narrativas com gestores educacionais, grupos juvenis ligados ao movimento hip hop, 
grupos de discussão com adolescentes, entrevistas narrativas com especialistas, entrevista narrativa com professores, trajetória de vida de jovens negras e ações afirmativas, juventude e gênero (Weller, 2011; Weller \& Pfaff, 2013; Goss, 2013; Silva, 2019). Essas pesquisas empíricas constituem um marco na construção e reconstrução de teorias e a aplicação de métodos em outros contextos e um grande desafio para a criação de novos conhecimentos na área da educação.

Por fim, levando-se em consideração que a preocupação com os problemas de base na construção de estudos e pesquisas do ponto de vista metodológico é antiga no Brasil na área da educação (André \& Gatti, 2013), o grande destaque para a publicação desta obra no Brasil consiste no debate teórico de densidade extraordinária sobre os métodos que compõem a pesquisa social reconstrutiva. Os fundamentos da estratégia de pesquisa apresentados no livro consideram as discussões construídas de sua prática social, do conhecimento das ações práticas do cotidiano e a reconstrução das perspectivas dos atores sociais. Esse tipo de postura amplia a compreensão do universo epistemológico em relação aos problemas educacionais e promove o engajamento de pesquisadores com as realidades investigadas, de modo a contribuir para o avanço do conhecimento em educação e para a mudança nas ações educativas. Logo, a educação pode ser examinada a partir de diferentes perspectivas, tanto por parte do educador quanto da pessoa educada, e como uma interação entre os dois lados, que também é contextualizada socialmente. $\mathrm{O}$ processo pedagógico pode ser teoricamente refletido e, ao mesmo tempo, reconstruído empiricamente, porque o conceito de reconstrução está atrelado ao dia a dia daqueles que são objeto da pesquisa. A reconstrução da reconstrução acontece no momento em que o pesquisador incorpora o cotidiano escolar ao cotidiano da prática da pesquisa e estabelece uma relação reflexiva entre ação e reflexão, tornando-se um agente de mudanças, com seu senso crítico conforme a situação e problemáticas da comunidade escolar.

\section{Referências}

André, M., \& Gatti, B. A. (2013). A relevância dos métodos de pesquisa qualitativa em educação no Brasil. In W. Weller, \& N. Pfaff (Orgs.), Metodologias da pesquisa qualitativa em educação: Teoria e prática (3a. ed.) (pp. 29-38). Vozes.

Bohnsack, R. (2020). Pesquisa social reconstrutiva. Introdução aos métodos qualitativos. Vozes.

Goss, K. P. (2013). Trajetórias militantes: Análise de entrevistas narrativas com professores integrantes do Movimento Negro. In W. Weller, \& N. Pfaff(Orgs.), Metodologias da pesquisa qualitativa em educação: Teoria e prática (3a. ed.) (pp. 223-238). Vozes.

Silva, C. P. (2019). Educação, juventude e gênero: Vivências no meio rural. Revista de Artes e Humanidades (online), 19, 1-24.

Weller, W. (2011). Minha voz é tudo o que eu tenho - Manifestaçôes juvenis em Berlim e São Paulo. UFMG.

Weller, W. (2020). Prefácio à edição brasileira. In R. Bohnsack, Pesquisa social reconstrutiva. Introdução aos métodos qualitativos. Vozes.

Weller, W., \& Pfaff, N. (Orgs.). (2013). Metodologias da pesquisa qualitativa em educação: Teoria e prática. (3a. ed.). Vozes.

\section{Como citar esta resenha}

Vieira, K. L. (2021). A reconstrução do conhecimento na pesquisa social e educação. [Resenha do livro Pesquisa Social Reconstrutiva. Introdução aos métodos qualitativos, de R. Bohnsack]. Cadernos de Pesquisa, 51, e07828. https://doi.org/10.1590/198053147828

Recebido em: 27 JULHO 2020 | Aprovado para publicação em: 04 DEZEMBRO 2020 